\section{CoAPO5 as a water oxidation catalyst and a light sensitizer $\dagger$}

\author{
Simone Zanarini, ${ }^{* a}$ Svetoslava Vankova, ${ }^{a}$ Simelys Hernandez, ${ }^{b}$ Vijaykumar S. Ijeri, ${ }^{a c}$ \\ Marco Armandi, ${ }^{b}$ Edoardo Garrone, ${ }^{* a}$ Barbara Bonelli, ${ }^{a}$ Barbara Onida ${ }^{a}$ and Paolo Spinelli $* a$
}

Received 14th December 2011, Accepted 16th April 2012

DOI: $10.1039 / \mathrm{c} 2 \mathrm{cc17827c}$

We report the first use of cobalt aluminophosphate (CoAPO5) as a water oxidation catalyst. A decrease in the overvoltage by about $0.2 \mathrm{~V}$ with respect to catalyst free FTO has been observed. Additionally, we show that CoAPO5, deposited on ITO or Pt, can also act as a photo-electro-catalyst, as it generates enhanced oxidation currents in the presence of light starting from a bias of $+0.8 \mathrm{~V}$ vs. Ag/AgCl.

Several classes of materials are available today for water photosplitting such as doped $\mathrm{TiO}_{2},{ }^{1-3}$ nanostructured $\mathrm{Fe}_{2} \mathrm{O}_{3},{ }^{4-6}$ inorganic semiconductors, ${ }^{7,8} \mathrm{Mn}$ based catalysts ${ }^{9}$ and many others. ${ }^{10,11}$ Recently the promising features of Co-based catalysts for water photosplitting have been reported by several groups. ${ }^{12}$ In the search for new materials different aspects must be considered such as efficiency, low cost, wide availability of the ingredients and durability. Another fundamental goal is to obtain a single material acting both as a water oxidation catalyst and as a photosensitizer, so as to avoid the use of two different materials for example $\mathrm{Ru}(\mathrm{bpy})_{3}{ }^{2+}$ as a light absorber and $\mathrm{Co}$ (III) for water oxidation catalysis. ${ }^{10,11}$

Considering the rising importance of Co-based materials, ${ }^{12}$ we report for the first time the photoelectrochemical properties of the well known system CoAPO5. This zeolite-like material, when incorporated into Nafion ${ }^{\circledR}$ films supported on conductive layers of FTO or Pt, appears to behave at the same time as a water oxidation catalyst as well as a visible light photosensitizer. MeAPO systems (where $\mathrm{Me}=\mathrm{Co}, \mathrm{Fe}, \mathrm{Mn}$ ) were used as catalysts under dry conditions in several catalytic processes. ${ }^{13-16}$

${ }^{a}$ Dipartimento di Scienza dei Materiali e Ingegneria Chimica,

Politecnico di Torino, corso Duca degli Abruzzi 20bis, 10129 Torino, Italy

${ }^{b}$ Center for Space Human Robotics, Istituto Italiano di Tecnologia, IIT@POLITO, Corso Trento 21, 10129 Torino, Italy

${ }^{c}$ Grauer \& Weil (India) Ltd, Akurli Road, Kandivali (E), Mumbai 400101, India

$\dagger$ Electronic supplementary information (ESI) available: Hydrothermal synthesis of CoAPO5; characterization of product; XRD spectrum, UV-VIS analysis of CoAPO5; electrochemical and photoelectrochemical setup; FTO/Nafion/CoAPO5 photoanode preparation; estimation of photons to "holes" conversion quantum yield; oxygen and hydrogen evolution measurements by gas chromatography (GC); scheme of the experimental setup for photoelectrochemical measurements; relative positions of light sources and photoanodes; view of the setup for combined electrochemical and gas chromatographic measurements; photocurrent $v s$. time of FTO/Nafion (blank); UV-VIS spectrum of calcinated CoAPO5; current vs. time plot for Pt/Nafion and $\mathrm{Pt} / \mathrm{Nafion} / \mathrm{CoAPO} 5$ photoanodes; effect of UV filtering on FTO/Nafion/CoAPO5 photocurrent. See DOI: $10.1039 / \mathrm{c} 2 \mathrm{cc} 17827 \mathrm{c}$
However, to the best of our knowledge, there is no report on their use in water oxidation and photocatalysis.

CoAPO5 with a Co content of $3 \% \mathrm{w} / \mathrm{w}$ was prepared following a standard procedure. ${ }^{17}$ The reader is referred to $\mathrm{ESI} \dagger$ for details on the preparation and characterization, which show, as a whole, that the sample prepared has the features of literature samples. The ESI $\dagger$ also shows that, after calcination and soaking in water, absorption in the UV-visible is basically related to $\mathrm{Co}$ (II).

Indeed, the UV-VIS absorption spectrum (Fig. S2, ESI $\dagger$ ) shows two peaks at 578 and $629 \mathrm{~nm}$, related to charge transfer processes from $\mathrm{Co}$ (II) to the APO framework. ${ }^{18}$ The fact that the hydrated CoAPO5 sample captures photons in the range of 300-700 nm clearly indicates the possibility of using this porous material as a solar light sensitizer.

The photoanode was prepared by drop casting $0.2 \mathrm{ml}$ of Nafion ${ }^{\circledR}(5 \% \mathrm{w} / \mathrm{W}$ in isopropyl alcohol) solution containing $20 \mathrm{mg}$ of dispersed CoAPO5 on a $2 \times 2 \mathrm{~cm}$ FTO (Fluorine Doped Tin Oxide slide, $R=30 \mathrm{Ohm} \times \mathrm{cm}$ ). The slides were dried for $12 \mathrm{~h}$ after deposition at room temperature. A Nafion ${ }^{\circledR}$ film without CoAPO5 was used as a blank. The electrocatalytic effect of CoAPO5 was monitored in a double compartment electrochemical cell by using the FTO/Nafion/ CoAPO5 as working-, a platinum foil as counter- and sat. $\mathrm{Ag} / \mathrm{AgCl}$ as reference electrode in a $0.1 \mathrm{M} \mathrm{K}_{2} \mathrm{SO}_{4}$ aqueous solution. Comparison of the CVs of FTO/Nafion/CoAPO5 and the blank shows that water oxidation potential is decreased by about $200 \mathrm{mV}$ in the presence of the catalyst (Fig. 1 and Table 1). These data are particularly significant considering the insulating nature of CoAPO5. ${ }^{19}$ Additional evidence comes from the current recorded at $+1.7 \mathrm{~V}$ that increases from 0.15 to $1.3 \mathrm{~mA}$ with the catalyst electrode (Table 1).

Subsequently, using the same electrode-electrolyte system, photoelectrochemical investigations were performed inside a darkroom. A plasma lamp that reproduces the solar spectra was used as a light source to illuminate the electrodes (intensity $1000 \mathrm{~W} \mathrm{~m}^{-2}$, see ESI $\dagger$ for details). A fixed potential of $+1.6 \mathrm{~V}$ vs. $\mathrm{Ag} / \mathrm{AgCl}$ was applied during the run to establish the water oxidation regime, and photocurrents were measured. The first $180 \mathrm{~s}$ were necessary to reach a steady state (plateau limit current under dark conditions), so as to make the detection of light-induced current steps more accurate. From 180 to $480 \mathrm{~s}$ the light source was switched $\mathrm{ON}$ in front of the cell (Fig. 2 and Table 1). By comparing the behaviour of the CoAPO5 photoanode and the blank (Fig. S8, ESI $\dagger$ ) an increase in current of 


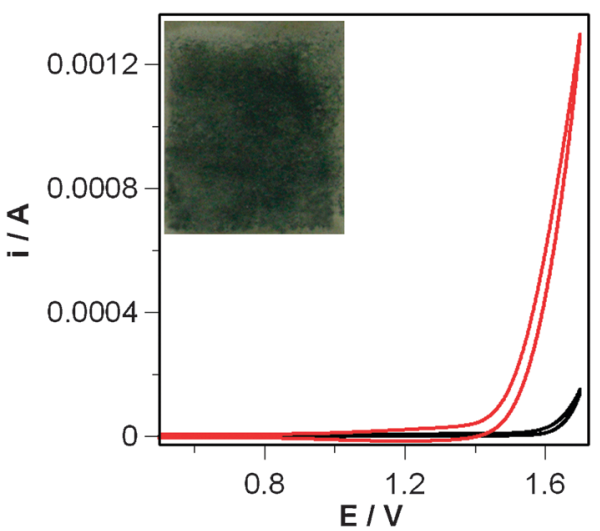

Fig. 1 Cyclic voltammetric curves of FTO slides $(R=30 \mathrm{Ohm} \times \mathrm{cm})$ coated by Nafion ${ }^{\circledR}$ films only (blank, black curves) and Nafion/ CoAPO5 films (red curves). Solution: $0.1 \mathrm{M} \mathrm{K}_{2} \mathrm{SO}_{4}$ in water. Scan rate $0.1 \mathrm{~V} \mathrm{~s}^{-1} .20 \mathrm{mg}$ of catalyst was added on the slide dispersed in $0.3 \mathrm{~mL}$ of $5 \% \mathrm{w} / \mathrm{w}$ Nafion ${ }^{\circledR}$ isopropanol solution. Inset: picture of the FTO/Nafion/CoAPO5 photoanode.

Table 1 Summary of electrochemical and photoelectrochemical properties of CoAPO5 and blank photoanodes

\begin{tabular}{|c|c|c|c|c|}
\hline & $\begin{array}{l}E \text { where water } \\
\text { oxidation begins }^{a} / \mathrm{V}\end{array}$ & $\begin{array}{l}i(+1.7 \mathrm{~V}) / \\
\mu \mathrm{A}\end{array}$ & $\begin{array}{l}\Delta i_{\text {direct }}^{b} \\
(60 \mathrm{~s}) / \mu \mathrm{A}\end{array}$ & $\begin{array}{l}\Delta i_{\text {direct }} \\
(400 \mathrm{~s}) / \mu \mathrm{A}\end{array}$ \\
\hline $\begin{array}{l}\text { FTO/Nafion/ } \\
\text { CoAPO5 }\end{array}$ & +1.43 & 1299 & 125.2 & 354 \\
\hline FTO/Nafion & +1.63 & 152 & 10.7 & 54.8 \\
\hline
\end{tabular}

${ }^{a}$ E vs. sat. $\mathrm{Ag} / \mathrm{AgCl}$. Solution: $0.1 \mathrm{M} \mathrm{K}_{2} \mathrm{SO}_{4}$ in water, scan rate $0.1 \mathrm{~V} \mathrm{~s}^{-1}$.

${ }^{b} \Delta i_{\text {direct }}(t)=i(180+t)-i(180)$ during a chronoamperometry at $+1.6 \mathrm{~V}$ fixed potential. Please note that at $t=180 \mathrm{~s}$ light is turned on (direct illumination, intensity: 1 sun). Solution: $0.1 \mathrm{M} \mathrm{K}_{2} \mathrm{SO}_{4}$ in water.

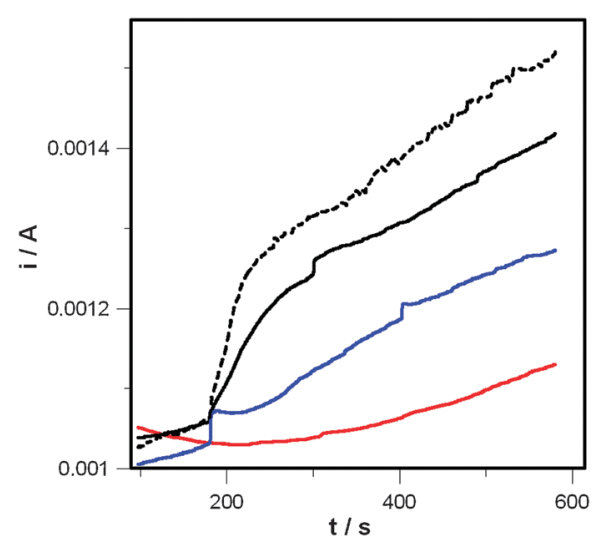

Fig. 2 Current vs. time curve for the FTO/Nafion/CoAPO5 photoanode under different illumination conditions (Scheme S2 (ESI $\dagger$ ) for setup): (i) dark room conditions (red curve); (ii) transversal illumination (blue curve); (iii) direct illumination (black curve); (iv) reverse illumination (broken curve). Solution: $0.1 \mathrm{M} \mathrm{K}_{2} \mathrm{SO}_{4}$ in water. Light program: 0-180 s dark; $180-580 \mathrm{~s}$ with light intensity of $1000 \mathrm{~W} \mathrm{~m}^{-2}$. $E=+1.6 \mathrm{~V}$ vs. $\mathrm{Ag} / \mathrm{AgCl}$.

ca. $125 v s .10 \mu \mathrm{A}$ was evidenced after 60 seconds. Interestingly, this current difference between the Co containing sample and the blank goes on increasing with time, reaching a value of ca. $350 \mu \mathrm{A}$ after $400 \mathrm{~s}$. The formation of $\mathrm{H}_{2}$ and $\mathrm{O}_{2}$ during illumination was confirmed by GC measurements as described in ESI $\dagger$ (Fig. S6 and S7). The presence of an illuminated
CoAPO5 catalyst increased the water oxidation current by $30-40 \%$ with respect to dark conditions (Fig. 2 and Fig. S4, ESI $\dagger$ ), providing evidence of its activity in the light driven $\mathrm{O}_{2}$ production. The quantum yield of CoAPO5 upon electron-hole generation with respect to incident photons has been estimated to be $0.20-0.25 \%$ as discussed in ESI $\dagger$ (Fig. S4 and S5).

The black curve in Fig. 2 shows, for CoAPO5, two well separated regions, a first "step-like" one ending at about $300 \mathrm{~s}$ and a second linear one.

Measurements with two different angles of light incidence (direct/transversal) were compared to cancel out the effect of a rise in temperature due to illumination, as well as any other possible spurious phenomenon (see Scheme S2, ESI $\dagger$ ). Indeed, the blue curve (transversal illumination) parallels the later stages of the blank experiment (red curve), indicating that the linear increase is not really related to the presence of light. The difference between the current during direct and transversal illumination reaches a plateau after $250 \mathrm{~s}$ of illumination, thus indicating again that after that time the increase in current is related to spurious phenomena. Under the adopted conditions, the $\mathrm{FTO} / \mathrm{Nafion}^{\circledR}$ films yield a small photocurrent, because FTO is a large bandgap semiconductor (ca. $3.8 \mathrm{eV}$ ) and the discharge lamp has $5 \%$ of UV light; such a photocurrent is about $10 \mu \mathrm{A}$ (Fig. S8, ESI $\dagger$ ).

When the FTO/Nafion/CoAPO5 photoanode is backilluminated (Scheme S2, ESI $†$, broken curve in Fig. 2), a photocurrent is observed, which is larger than that recorded under frontal illumination by $c a$. $10 \mu \mathrm{A}$, i.e. the FTO contribution. This is because, in back-illumination the FTO is not shielded by the greyish CoAPO5 layer as in direct illumination.

Finally, it is worthy of note that no effect is observed when the UV component of the lamp light has been filtered off. This finally shows that the light used in the photochemical process is absorbed by CoAPO5 (Fig. S9, ESI $\dagger$ ).

To rule out any important role of the FTO support in the photoactivity, data have been obtained by testing the catalyst on a Pt slide. $20 \mathrm{mg}$ of CoAPO5 were dispersed in $0.3 \mathrm{~mL}$ of $5 \% \mathrm{~W} / \mathrm{W}$ Nafion ${ }^{\mathbb{R}}$-isopropanol solution and sonicated for 15 minutes. The suspension was then dropped onto a $4 \mathrm{~cm}^{2}$ Pt slide and left to dry for $12 \mathrm{~h}$ as done for the FTO substrate. The Pt/Nafion ${ }^{\circledR} /$ CoAPO5 slide was then used as a photoanode under the same experimental conditions as before and photocurrent was measured upon direct illumination (Fig. S10, ESI $\dagger$ ). The chronoamperometry shows a neat increase in current with respect to blank Pt/Nafion ${ }^{\circledR}$ when light is turned on $(\sim 6 \mathrm{~mA})$, showing that the increase in current is associated only with CoAPO5.

Let us now consider the energy levels involved in electron transfer in the case of FTO/Nafion ${ }^{\circledR} / \mathrm{CoAPO} 5$ (Scheme 1). The water oxidation reaction is based on the reduction of $\mathrm{Co}(\mathrm{III})$ centres to $\mathrm{Co}$ (II) species, according to the reaction shown in Scheme 1, that are generated again after the lightdriven electron transfer to FTO. For CoAPO5, UV-VIS spectra indicate an energy difference of $c a .2 .0 \mathrm{eV}$ (Co(II) related transitions), ${ }^{18}$ whereas in the case of FTO the difference between valence and conduction bands is $c a .3 .8 \mathrm{eV}^{7}$. Because light exposure populates the CoAPO5 excited state (CoAPO5*), the minimum potential necessary for producing photocurrent 


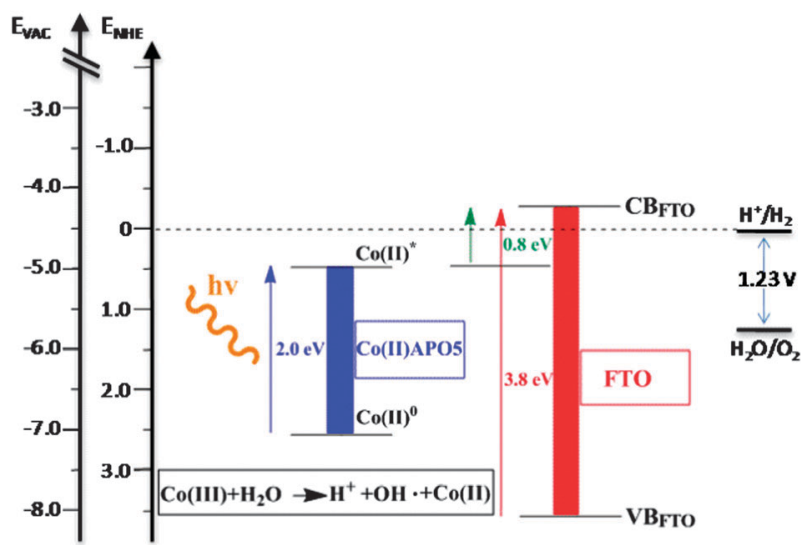

Scheme 1 Basic diagram of the states involved in photoinduced electron transfer from the fundamental level of CoAPO5 to the conduction band of FTO. Note that under illumination a minimum bias of $0.8 \mathrm{~V}$ is necessary to obtain a photocurrent.

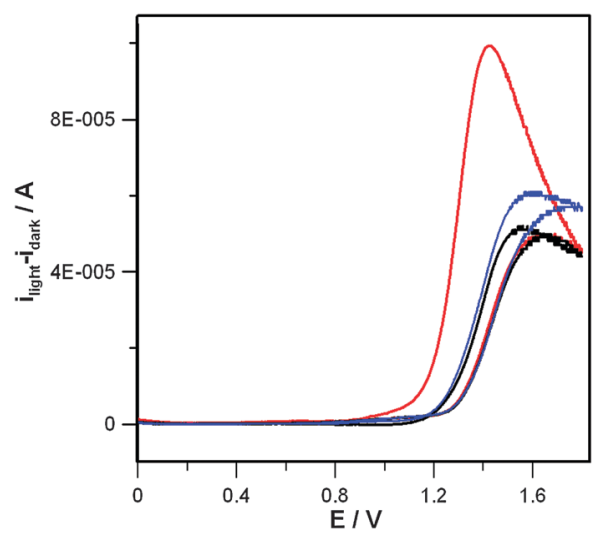

Fig. 3 Photocurrent vs. $E$ curve for the FTO/Nafion ${ }^{\circledR} / \mathrm{CoAPO} 5$ photoanode during three successive voltammetric scans. Red curve: first cycle; blue curve: second cycle; black curve: third cycle. Experimental conditions are the same as already described in Fig. 1 and 2. The photocurrent has been calculated by subtracting the stationary $\mathrm{CV}$ in the dark from the one recorded under frontal illumination.

equals the difference between CoAPO5* (electron donor level) and the conduction band of FTO (electron acceptor level). To measure this minimum potential for the onset of photocurrent, a photocurrent vs. E curve was obtained by subtracting the CV curve in the dark from the CV curve under illumination (Fig. 3). Each CV was repeated for 30 cycles until a stationary voltammetric curve was obtained. The value of potential where photocurrent is detected is $c a$. $+0.8 \mathrm{~V}$. Knowledge of such a value allows Scheme 1 to be drawn to scale, which shows that the transfer of an electron from $\mathrm{Co}(\mathrm{II})$ to the external circuit requires two contributions: the photoexcitation and a bias of at least $+0.8 \mathrm{~V} v s . \mathrm{Ag} / \mathrm{AgCl}$ (Scheme 1).

The electrochemical results obtained using FTO and Pt substrates indicate that CoAPO5 acts as a combined water oxidation catalyst and visible light sensitizer. Indeed, it generates water oxidation currents in the presence of light starting from a bias of $+0.8 \mathrm{~V} v s . \mathrm{Ag} / \mathrm{AgCl}$. Considering the low cost, wide availability of reactants and easy preparation this porous material appears to be of interest for water photosplitting. Work is in progress to increase the maximum photocurrent by preparing nanostructured thin films to minimize the electron transfer distance and increasing the amount of accessible catalytic centres.

This research has been carried out in the context of the European Project "SOLHYDROMICS".

\section{Notes and references}

1 R. Asahi, T. Morikawa, T. Ohwaki, K. Aoki and Y. Taga, Science, 2001, 293(5528), 269

2 W. Choi, A. Termin and M. R. Hoffmann, J. Phys. Chem., 1994, 98(51), 13669

3 X. Chen and S. S. Mao, Chem. Rev., 2007, 107(7), 2891.

4 K. Sivula, F. Le Formal and M. Gratzel, Chem. Mater., 2009 , 21, 2862.

5 F. Le Formal, M. Grätzel and K. Sivula, Adv. Funct. Mater., 2010, 20, 1099.

6 K. Sivula, R. Zboril, F. Le Formal, R. Robert, A. Weidenkaff, J. Tucek, J. Frydrych and M. Grätzel, J. Am. Chem. Soc., 2010, 132, 7436 .

7 M. Gratzel, Nature, 2001, 414, 338

8 O. Khasalev and J. Turner, Science, 1997, 280, 425.

9 C. S. Mullins and V. L. Pecoraro, Coord. Chem. Rev., 2008, 252, 416.

10 A. Hagfeldt, G. Boschloo, L. Sun, L. Kloo and H. Pettersson, Chem. Rev., 2010, 110(11), 6595.

11 M. G. Walter, E. L. Warren, J. R. McKone, S. W. Boettcher, Q. Mi, E. A. Santori and N. S. Lewis, Chem. Rev., 2010, 110(11), 6446.

12 (a) J. B. Gerken, J. G. McAlpin, J. Y. C. Chen, M. L. Rigsby, W. H. Casey, R. D. Britt and S. S. Stahl, J. Am. Chem. Soc., 2011, 133(36), 14431; (b) M. Barroso, A. J. Cowan, S. R. Pendlebury, M. Grätzel, D. R. Klug and J. R. Durrant, J. Am. Chem. Soc., 2011, 133(38), 14868; (c) N. S. McCool, D. M. Robinson, J. E. Sheats and G. C. Dismukes, J. Am. Chem. Soc., 2011, 133(30), 11446; (d) V. Artero, M. Chavarot-Kerlidou and M. Fontecave, Angew. Chem., Int. Ed., 2011, 50(32), 7238; (e) Y. Surendranath, M. W. Kanan and D. G. Nocera, J. Am. Chem. Soc., 2010, 132, 16501; (f) M. W. Kanan and D. G. Nocera, Science, 2008, 321(5892), 1072.

13 J. Meusinger, H. Vinek and J. A. Lercher, J. Mol. Catal., 1994, 87(2), 263.

14 J. Meusinger, H. Vinek, G. Dworeckow, M. Goepper and J. Lercher, Stud. Surf. Sci. Catal., 1991, 69(C), 373.

15 Y. He, M. Dong, J.-F. Li, J.-G. Wang and W. Fan, Acta Phys.-Chim. Sin., 2010, 26(5), 1305.

16 S.-M. Yang, J.-Y. Lin, D.-H. Guo and S.-G. Liaw, Appl. Catal., A, 1999, 181(1), 113

17 S. T. Wilson and E. M. Flanigen, US Pat., 4567,029, 2003.

18 (a) E. Schoonheydt, R. A. Vos, R. Pelgrims and H. Leeman, Stud. Surf. Sci. Catal., 1989, 49(A), 559; (b) B. Kraushaar-Czarnetzki, W. G. M. Hoogervorst, R. R. Andréa, C. A. Emeis and W. H. J. Stork, J. Chem. Soc., Faraday Trans., 1991, 87(6), 891; (c) A. Frache, L. Marchese, M. Cadoni, S. Coluccia, B. Palella, R. Pirone and P. Ciambelli, Stud. Surf. Sci. Catal., 2001, 140, 269.

19 A. Paul, M. Prabu, G. Madras and S. Natarajan, J. Chem. Sci., 2010, 122(5), 771 . 